\title{
Ülkelerin Yaşam Kalitelerine Göre Değerlendirilmesi İçin Hibrit Pisagor Bulanık Ahp-Topsis Metodolojisi: Avrupa Birliği Örneği
}

\author{
Aslıhan Yıldız ${ }^{*}$, Ertuğrul Ayyıldız ${ }^{2}$, Alev Taşkın Gümüşş ${ }^{3}$ Coşkun Özkan ${ }^{4}$ \\ ${ }^{1}$ Yıldız Teknik Üniversitesi, Makine Fakültesi, Endüstri Mühendisliği Bölümü, İstanbul, Türkiye (ORCID: 0000-0001-5288-7967) \\ ${ }^{2}$ Yıldız Teknik Üniversitesi, Makine Fakültesi, Endüstri Mühendisliği Bölümü, İstanbul, Türkiye (ORCID: 0000-0002-6358-7860) \\ ${ }^{3}$ Yıldız Teknik Üniversitesi, Makine Fakültesi, Endüstri Mühendisliği Bölümü, İstanbul, Türkiye (ORCID: 0000-0003-1803-9408) \\ ${ }^{4}$ Yıldız Teknik Üniversitesi, Makine Fakültesi, Endüstri Mühendisliği Bölümü, İstanbul, Türkiye (ORCID: 0000-0002-0318-8614)
}

(İlk Geliş Tarihi 2 Aralık 2019 ve Kabul Tarihi 31 Aralık 2019)

(DOI: 10.31590/ejosat.658021)

ATIF/REFERENCE: Yıldız, A., Ayyıldız, E., Gümüş, A. T. \& Özkan, Ç. (2019). Ülkelerin Yaşam Kalitelerine Göre Değerlendirilmesi İçin Hibrit Pisagor Bulanık Ahp-Topsis Metodolojisi: Avrupa Birliği Örneği. Avrupa Bilim ve Teknoloji Dergisi, (17), 1383-1391.

$\ddot{O} z$

Çalışmada, Avrupa Birliği (AB) üyesi otuz bir ülke analiz edilmiştir. Avrupa Birliğinin, ülkelerin yaşam kalitesini değerlendirmek amacıyla belirlediği kriterler incelenerek, literatür taraması ve uzman görüşleri yardımıyla kriterler güncellenmiştir. Bu kriterler, ekonomik ve sosyal kalkınmanın temel ölçülerinden olan ve farklı yönleri temsil eden dokuz kriter olarak özetlenebilir. Bu dokuz kriter Yaşam Koşulları, Çalışma Durumu, Eğitim, Sağlık, Sosyal İlişkiler, Güvenlik, Yönetim, Çevre ve Barınma olarak belirlenmiştir. Ardından uzmanların kriterler hakkındaki görüşleri Modifiye Delphi Yöntemi ile birleştirilmiştir. Kriter ağırlıkları, Pisagor Bulanık AHP yöntemi ile Modifiye Delphi Yöntemi'nden elde edilen ikili kıyaslama matrisi kullanılarak elde edilmiştir. Daha sonra otuz bir ülke arasında yaşam kalitesine göre sıralama yapmak amacıyla TOPSIS yöntemi kullanılmıştır.

\section{Pythagorean Fuzzy AHP-Topsİs Methodology for the Evaluatİon of Countries According To Life Quality: European Unıon Case}

\begin{abstract}
Thirty-one member countries of the European Union (EU) were analyzed within the study. The criteria determined by the European Union to evaluate the quality of life of the countries were examined and updated with the literature review and experts' opinions. These quality of life criteria can be summarized as nine criteria which are the basic measures of economic and social development and represent different aspects. These nine criteria were determined as Material Living Conditions, Working Status, Health, Education, Social Relations, Safety, Governance and Basic Rights, Natural and Living Environment, and Housing. Then, the opinions of the experts about the criteria were consolidated with the Modified Delphi Method. The weights of each criterion were obtained by the Pythagorean Fuzzy AHP method using pairwise comparison matrix obtained from the Modified Delphi Method. Then, TOPSIS method was used to compare the quality of life among thirty-one countries.
\end{abstract}

Keywords: Pythagorean Fuzzy AHP, TOPSIS, Quality of Life, European Union.

\footnotetext{
* Sorumlu Yazar: Yıldız Teknik Üniversitesi, Makine Fakültesi, Endüstri Mühendisliği Bölümü, İstanbul, Türkiye, ORCID: 0000-0001-5288-7967, aslihany@yildiz.edu.tr
} 


\section{Giriş}

Dünya genelinde kullanılan teknoloji günden güne gelişmektedir. Gelişen teknoloji ile birlikte insanların yaşamı daha kolay hale gelmektedir. Bu da beraberinde daha kolay bir toplum yaşamı vadetmektedir. İnsan yaşamı kolaylaştıkça, toplumların refah seviyesi de bu durumla birlikte yükselmektedir. Bu gelişmeler sonucunda, refah seviyesini belirleyen en önemli bileşenlerden biri olan yaşam kalitesine verilen önem bu anlamda her geçen gün artmaktadır. Yaşam kalitesi terimi, bireylerin ve toplumların genel refahını ifade eder. Terim, uluslararası kalkınma, sağlık ve politika alanları dahil olmak üzere çok çeşitli alanlarda farklı anlamlarda kullanılmaktadır. Ekonomiye dayanan standart yaşamla karşılaştırılmaması gereken yaşam kalitesi; sadece ekonomi ve iş istihdamını değil, bunlarla birlikte çevreyi, fiziksel ve ruhsal sağlığı, eğitimi, sosyal imkanları ve daha birçok kavramı içermektedir. Yaşam kalitesinin yükselmesi ile birlikte, bireylerin ve toplumların yaratıcılığının, standartlarının yükseleceği düşünülebilir. (Ayyıldız ve Demirci, 2018). Yaşam kalitesi aynı zamanda bireylerin endişe seviyesini de belirleyen önemli faktörlerdendir (Halvari vd., 2019). Dünya Sağlık Örgütü yaşam kalitesi terimini, bireylerin yaşadıkları toplumdaki değer sistemleri ve genel olarak kültür algıları ile ilişkili olarak ifade etmektedir. Bireylerin ve toplumların yaşam kalitelerini, bireylerin beklentileri, endişeleri ve hedefleri ile birlikte toplumun standartları belirlemektedir (Whoqol Group, 1998).

Son yıllarda araştırmacıların ilgi odağı haline gelen yaşam kalitesinin belirlenmesi, literatürde sıkça çalışılan bir konu haline gelmiştir. Çalışmalarda çok kriterli karar verme (ÇKKV) genellikle başvurulan yöntemlerdendir. Offringa ve De Wet (1996) Afrika'nın temel sorunlarından olan temiz su ihtiyacını, yaşam kalitesini gözeterek önceliklendirirken ÇKKV tekniklerine başvurmuşlardır. Jeon vd. (2010) çalışmalarında Atlanta bölgesinin yaşam kalitesini arttıracak ulaşım sisteminin belirlenmesini ÇKKV yöntemleri kullanarak gerçekleştirmişlerdir. Chen (2011) bireyin yaşam kalitesini arttıran spor eğitiminde önemli faktörleri analizini DEMATEL ve ANP tekniklerini kullanarak yapmıştır. Mulliner vd. (2013) barınma özelinde yaşam kalitesini arttıracak etmenlerin karşılanabilirliğini COPRAS metoduyla incelemişlerdir. Anand vd. (2017) Hindistan özelinde yüksek yaşam kalitesi vaat eden akıllı şehirlerin sürdürülebilirliğini Bulanık AHP ve veri zarflama analizi kullanarak değerlendirmişlerdir. Zarghami vd. (2018) İran için yaşam kalitesini belirlemede kullanılan değişkenleri AHP tekniği ile incelemişlerdir. Devlin vd. (2018) İngiltere özelinde yaptıkları çalışmalarında sağlık temelli yaşam kalitesini değerlendirmek için yeni bir yöntem önermiş̧lerdir. Silverberg vd. (2018) hasta popülasyona odaklandıkları çalışmalarında, hastalığın yaşam kalitesini nasıl etkilediğini belirlemeye çalışmlışlardır. Wann-Ming (2019) gelişmekte olan kırsal yerleşimlerin yaşam kalitesini yükseltmek için ulaşım ağının nasıl oluşturulması gerektiğini araştırmıştır. Wong vd. (2019) Hong Kong’taki obez çocukların hastalıkla birlikte düşen yaşam kalitesinin nasıl yükseltilebileceğine dair öneriler sunmuşardır.

Çalışma kapsamında, otuz bir Avrupa Birliği (AB) üyesi ülke analiz edilmiştir. Bu ülkelerin yaşam kalitesine göre sıralanması amaciyla dokuz kriter belirlenmiş ve gerekli veriler Avrupa Birliği'nin resmi istatistik sitesinden (URL-1) elde edilmiştir. Kriterlerin çok kriterli karar verme (ÇKKV) yöntemleri kullanılarak önceliklendirilmesi amacıyla uzmanlardan alınan görüşler, bulanık mantık kullanılarak sayısallaştırılmıştır. Analitik Hiyerarşik Prosesi (AHP) kullanılarak kriterlerin belirlenmesinin ardından ÇKKV yöntemlerinden biri olan TOPSIS ile ülkeler yaşam kalitelerine göre sıralanmıştır. Çalışma kapsamında önerilen yöntem, ele alınan kriterler ve yapılan uygulama sonraki başlıklarda açıklanmıştır.

\section{2. Önerilen Yöntem}

Yapılan bu çalışmada, Avrupa Birliği'nin ülkelerin yaşam kalitesini değerlendirmek amacıyla belirlediği kriterler incelenmiştir. Daha sonra bu kriterler, literatür taraması ve uzman görüşleri yardımıyla güncellenmiştir. Ardından uzmanların kriterler hakkındaki görüşleri Modifiye Delphi Yöntemi ile birleştirilmiştir. Kriter ağırlıkları, Pisagor Bulanık AHP yöntemi ile Modifiye Delphi Yöntemi'nden elde edilen ikili kıyaslama matrisi kullanılarak elde edilmiştir. Daha sonra otuz bir ülke arasında yaşam kalitesine göre kıyaslama yapmak amacıyla TOPSIS yöntemi kullanılmıştır. Önerilen yöntem Şekil 1'de açıkça görülmektedir. Yöntemin aşamaları alt bölümlerde teorik olarak detaylandırılmıştır. 


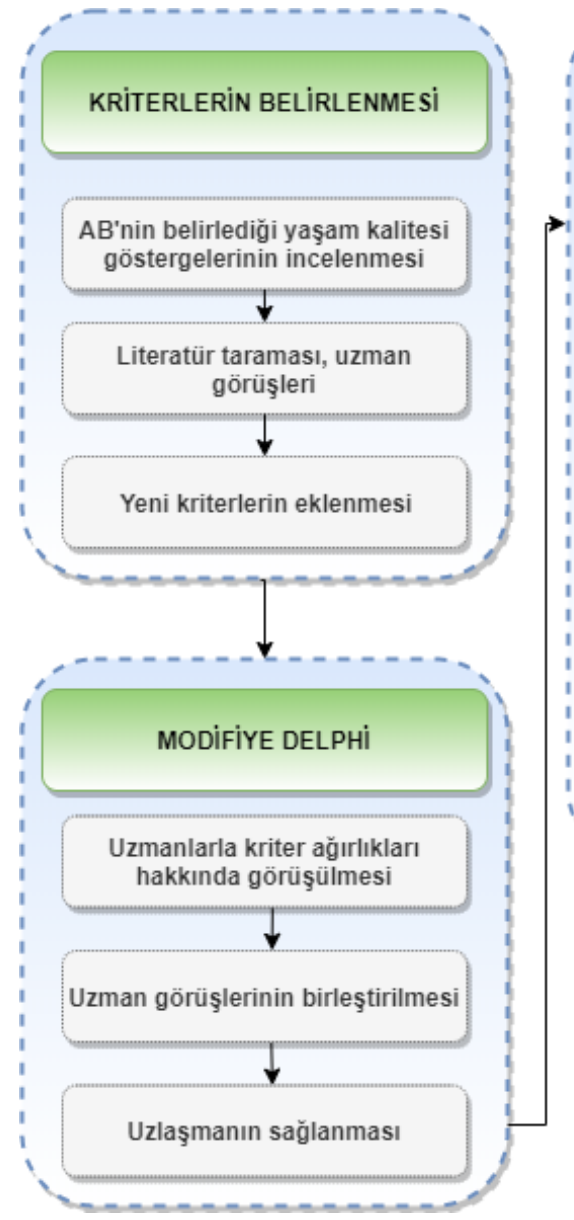

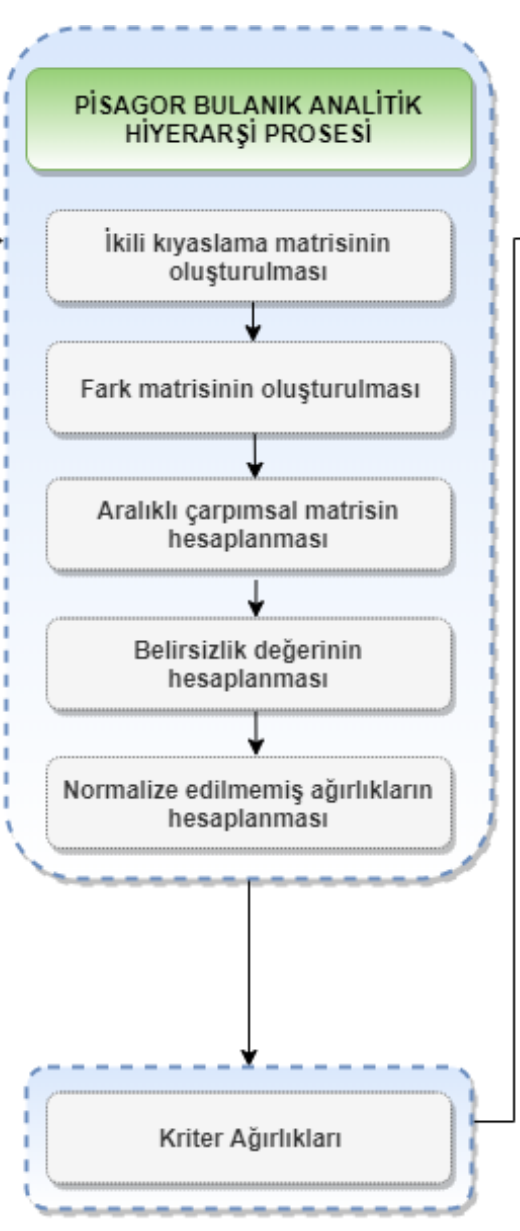

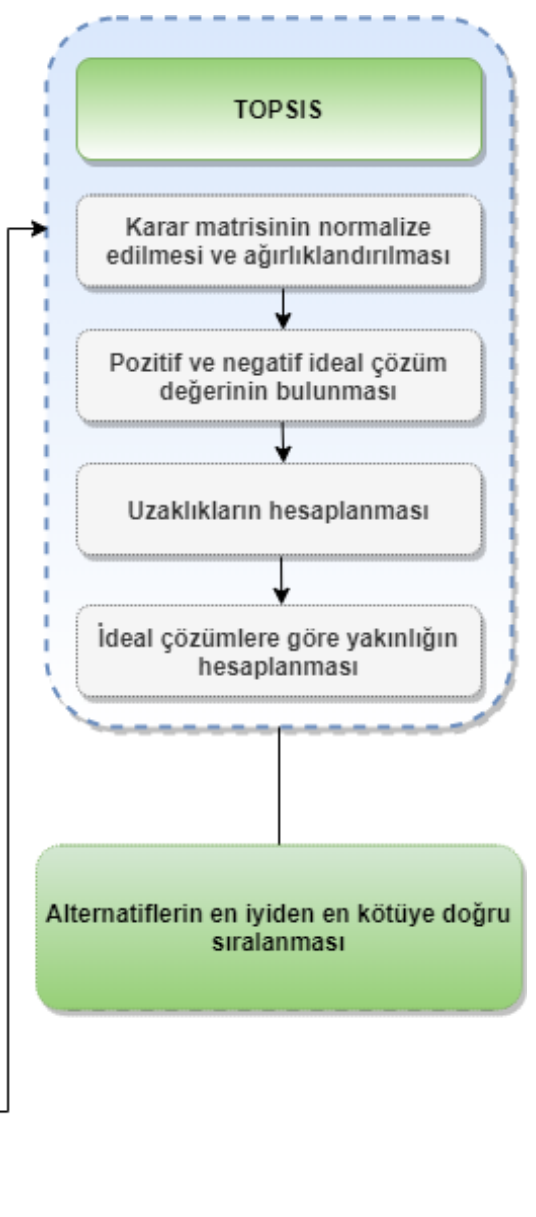

Şekil 1. Önerilen yöntem

\subsection{Kriterlerin Belirlenmesi}

Çalışma kapsamında kullanılacak kriterler belirlenirken, Avrupa Birliği’nin yayınladığı yaşam kalitesi göstergeleri temel alınmıştır. $\mathrm{Bu}$ yaşam kalitesi göstergeleri, ekonomik ve sosyal kalkınmanın temel ölçülerinden olan ve farklı yönleri temsil eden dokuz boyut olarak özetlenebilir. Bu dokuz boyut Yaşam koşulları, Çalışma Durumu, Eğitim, Sağlık, Sosyal İlişkiler, Güvenlik, Yönetim, Çevre ve Kişisel Yaşam Memnuniyeti (URL-1) olarak belirtilmiştir.

Yapılan literatür taramasına ve uzman görüşlerine göre "Kişisel Yaşam Memnuniyeti” kriteri yerine "Barınma” kriteri göz önüne alınmış ve dokuz kriter kullanılarak çalışma hazırlanmıştır. Ele alınan kriterler Şekil 2'de verilmiştir.

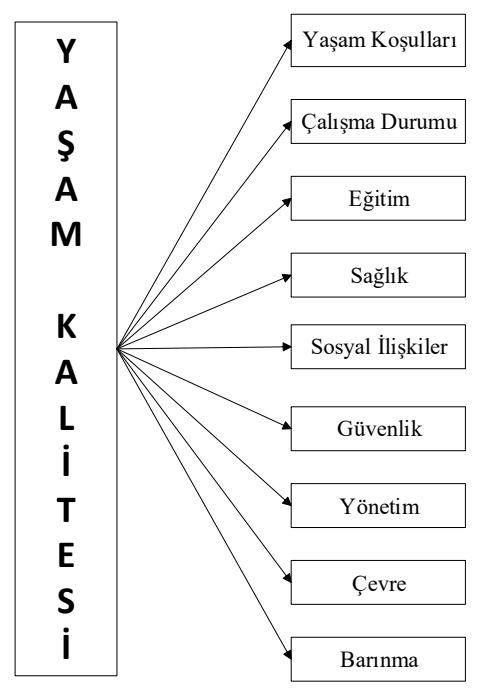

Şekil 2. Çalışmada kullanılan kriterler 


\subsection{Modifiye Delphi Methodu}

Bir konu hakkında karar verilirken, farklı uzmanlardan fikir almak gerekebilir. Bu uzmanlar; tecrübe ve uzmanlık alanlarına göre farklı görüşlere sahip olabilir. Bu gibi durumlarda Delphi yöntemi uygulanabilir. Delphi yöntemi, önceden belirlenmiş konuda, farklı iletişim kanallarıyla görüşülen uzmanların fikirlerini değerlendirerek analiz etmeye yardımcı olur (Gumus, 2009). Yöntemin adımları aşağıdaki gibidir.

Adım 1. Görüşleri alınacak uzmanların belirlenmesi,

Adım 2. Anketin uzmanlara ilk kez uygulanması,

Adım 3. Anketin uzmanlara ikinci kez uygulanması,

Adım 4. Anketin uzmanlara üçüncü kez uygulanması,

Adım 5. Uzman görüşlerinin birleştirilmesiyle uzlaşmanın sağlanması.

\subsection{Pisagor Bulanık Sayılar}

İnsanlar karar vermenin karmaşıklığı ve belirsizliği nedeniyle fikirlerini pek çok problemde tam olarak ifade edemezler. Bu nedenle; bulanık teori ortaya çıkmış ve literatüre Zadeh (1965) tarafından kazandırılmıştır. Teori, karar verme problemlerinin değerlendirme süreçlerinde öznel yargılama ve nitel değerlendirme için uygundur. Görüşlerin, dilsel olarak ifade edilebilmesine dayanan bu yaklaşım, bilgideki belirsizliği çözmek için etkili bir yöntemdir (Wang vd., 2015).

Sezgisel bulanık kümelerin belirsizliği tam anlamıyla ifade edememesinden dolayı Pisagor bulanık kümeleri Yager (2013) tarafından ortaya atılmış ve bazı durumlarda sezgisel bulanık kümelere genelleme olarak geliştirilmiştir (Gul ve Ak, 2018). Pisagor bulanık kümelerle ilgili bazı önemli tanımlar aşağıda verilmiştir (Karasan vd. 2018).

Tanım 1: Bir Pisagor bulanık kümesi $\widetilde{P}$ Eşitlik 1'deki gibi gösterilir (Yüceşan ve Kahraman, 2019):

$\widetilde{P} \cong\left\{x, \widetilde{P}\left(\mu_{\tilde{p}}(x), v_{\tilde{p}}(x)\right) ; x \in X\right\}$

$\mu_{\tilde{p}}(x): X \mapsto[0,1]$ ve $v_{\tilde{p}}(x): X \mapsto[0,1] x \in X$ in $\tilde{P}$ kümesine sirasıly üye olma ve üye olmama derecesini ifade eder ve kareleri toplamı Eşitlik 2'de gösterildiği gibi 1'i geçemez.

$0 \leq \mu_{\tilde{p}}(x)^{2}+v_{\tilde{p}}(x)^{2} \leq 1 ; x \in X$

Tereddüt derecesi Eşitlik 3 kullanılarak hesaplanır.

$\pi_{\tilde{p}}(x)=\sqrt{1-\mu_{\tilde{p}}(x)^{2}-v_{\tilde{p}}(x)^{2}}$

Pisagor bulanık kümelerdeki temel işlemler Tanım 2'de yer alan Eşitlik 4-7'de gösterilmiştir.

Tanım 2: $\beta_{1}=P\left(\mu_{\beta_{1}}, v_{\beta_{1}}\right)$ ve $\beta_{2}=P\left(\mu_{\beta_{2}}, v_{\beta_{2}}\right)$ iki Pisagor bulanık sayı olmak üzere işlemler aşağıdaki gibidir (Gul ve Ak, 2018; Mohagheghi vd., 2017):

$$
\begin{aligned}
& \beta_{1} \oplus \beta_{2}=\tilde{P}\left(\sqrt{\mu_{\beta_{1}}^{2}+\mu_{\beta_{2}}^{2}-\mu_{\beta_{1}}^{2} \mu_{\beta_{2}}^{2}}, v \beta_{1} v \beta_{2}\right) \\
& \beta_{1} \otimes \beta_{2}=\tilde{P}\left(\mu \beta_{1} \mu \beta_{2}, \sqrt{v_{\beta_{1}}^{2}+v_{\beta_{2}}^{2}-v_{\beta_{1}}^{2} v_{\beta_{2}}^{2}}\right) \\
& \beta_{1} \ominus \beta_{2}=\tilde{P}\left(\sqrt{\frac{\mu_{\beta_{1}}^{2}-\mu_{\beta_{2}}^{2}}{1-\mu_{\beta_{2}}^{2}}, \frac{v_{\beta_{1}}}{v_{\beta_{2}}}}\right) \text {, ĕger } \mu_{\beta_{1}} \geq \mu_{\beta_{2}}, v_{\beta_{1}} \leq \min \left\{v_{\beta_{2}}, \frac{v_{\beta_{2}} \cdot \pi_{\beta_{1}}}{\pi_{\beta_{2}}}\right\} \\
& \frac{\beta_{1}}{\beta_{2}}=\tilde{P}\left(\frac{\mu_{\beta_{1}}}{\mu_{\beta_{2}}} \sqrt{\frac{v_{\beta_{1}}^{2}-v_{\beta_{2}}^{2}}{1-v_{\beta_{2}}^{2}}}\right) \text {, ĕger } \mu_{\beta_{1}} \leq \min \left\{\mu_{\beta_{2}}, \frac{\mu_{\beta_{2}} \cdot \pi_{\beta_{1}}}{\pi_{\beta_{2}}}\right\}, v_{\beta_{1}} \geq v_{\beta_{2}}
\end{aligned}
$$

\subsection{Pisagor Bulanık AHP}

Belirlenmiş kriterleri dikkate alarak alternatiflerin ikili karşılaştırılması esasına dayanan çok kriterli karar verme yöntemlerinden biri olan AHP (Çavdur, vd. 2019) yönteminde objektif ve sübjektif kriterlerin kıyaslanması yapılabilir (Yerlikaya ve Arıkan, 2016). Yöntem karar vericilerin kararlarında tutarlı olmasını sağlarken, aynı zamanda basit ikili kıyaslamalarla karar vericilerin işini kolaylaştııır (Ecer, vd. 2018). AHP yöntemi, uzmanlardan bilgi alsa bile, insanın düşünce tarzını tam olarak yansıtmamaktadır. Bu nedenle, AHP ile bulanık mantık birleştirilerek Bulanık AHP ortaya çıkmıştır. Geleneksel AHP yönteminden farklı olarak net değerlerin 
yerine, Bulanık AHP yönteminde karşılaştırma oranları bir dizi değer kullanılarak belirlenir (Liu ve Jin, 2012). Pisagor bulanık kümeleri, belirsizliği ortadan kaldırmak için AHP yöntemine entegre edilebilir. Pisagor Bulanık AHP yönteminin adımları aşağıdaki gibidir.

Adım 1: Dilsel değişkenlere dayalı ikili karşılaştırma matrisi $A=\left(a_{i j}\right)_{m x m}$ oluşturulur.

Adım 2: Eşitlik 8 ve Eşitlik 9 kullanılarak farklar matrisi $D=\left(d_{i j}\right)_{m x m}$ oluşturulur.

$d_{i j_{L}}=\mu_{i j_{L}}{ }^{2}-v_{i j_{L}}{ }^{2}$

$d_{i j_{L}}=\mu_{i j_{U}}{ }^{2}-v_{i j_{U}}{ }^{2}$

Adım 3: Çarpımsal matris $S=\left(s_{i j}\right)_{m x m}$ Eşitlik 10 ve Eşitlik 11 kullanılarak hesaplanır.

$s_{i j_{L}}=\sqrt{1000^{d_{i j_{L}}}}$

$s_{i j_{U}}=\sqrt{1000^{d_{i j}}}$

Adım 4: Tereddüt dereceleri $H=\left(h_{i j}\right)_{m x m}$ Eşitlik 12 kullanılarak belirlenir.

$h_{i j}=1-\left({\mu_{i j_{U}}}^{2}-{\mu_{i j_{L}}}^{2}\right)-\left({v_{i j_{U}}}^{2}-{v_{i j_{L}}}^{2}\right)$

Adım 5: Normalize edilmemiş ağırlıklar $T=\left(t_{i j}\right)_{m x m}$ Eşitlik 13 yardımıyla hesaplanır.

$t_{i j}=\left(\frac{s_{i j_{L}}+s_{i j_{U}}}{2}\right) h_{i j}$

Adım 6: Kriter ağırlıkları $w_{i}$ Eşitlik 14 kullanılarak belirlenir.

$w_{i}=\frac{\sum_{i=1}^{m} t_{i j}}{\sum_{i=1}^{m} \sum_{j=1}^{m} t_{i j}}$

\subsection{TOPSIS}

Hwang ve Yoon (1981) tarafindan geliştirilmiş ve literatüre kazandırılan TOPSIS yöntemi karar verme problemlerinde sağladığı kolaylık açısından çok geniş bir uygulama alanına sahiptir. Alternatifler içerisinden yapılacak seçimin temelinde ideal çözüme yakınlık ve ideal olmayan çözüme uzaklık yer almaktadır (Yalçınkaya, vd. 2018). Yöntem basit ve anlaşılabilir olmakla beraber iyi bir hesaplama etkinliğine sahiptir (Oruç ve Kılınç, 2019). Yöntemin temel adımları aşağıdaki gibidir (Alizadeh vd. 2016).

Adım 1: Karar matrisi $A=\left(a_{i j}\right)_{n x m}$ oluşturulur. $n$ alternatif sayısını $m$ kriter sayısını göstermektedir.

Adım 2: Karar matrisi Eşitlik 15 kullanılarak normalize edilir.

$\frac{a_{i j}}{\sqrt{\sum_{i=1}^{m} a_{i j}{ }^{2}}}$

Adım 3: Ağırlıklandırılmış normalize matris $V=\left(v_{i j}\right)_{n x m}$ Eşitlik 16 kullanılarak oluşturulur.

$v_{i j}=w_{j} a_{i j}$

Adım 4: Pozitif ve negatif ideal çözüm değerleri elde edilir.

Ağırlıklandırılmış normalize matris elde edildikten sonra, her bir sütunun en iyi değeri problem yapısı dikkate alınarak belirlenir. Eğer kriter, fayda kriteri ise her sütunun maksimum değeri belirlenirken, maliyet kriterlerinde ise minimum değer dikkate alınır. En iyi değerler artık pozitif ideal çözüm değerleri olarak adlandırılırlar $\left(v_{j}^{+}\right)$. Daha sonra da her bir sütun için en kötü değerler belirlenir. En kötü değerler ise artık negatif ideal çözüm olarak adlandırılır $\left(v_{j}^{-}\right)$.

Adım 5: Pozitif ideal çözüm değerine uzaklık Eşitlik 17, negatif ideal çözüm değerine uzaklık ise Eşitlik 18 kullanılarak belirlenir.

$$
\begin{aligned}
& S^{+}=\sqrt{\sum_{j=1}^{n}\left(v_{i j}-v_{j}^{+}\right)^{2}} \\
& S^{-}=\sqrt{\sum_{j=1}^{n}\left(v_{i j}-v_{j}^{-}\right)^{2}} \\
& \text { e-ISSN: } 2148-2683
\end{aligned}
$$


Adım 6: İdeal çözüme göre yakınlık Eşitlik 19 kullanılarak hesaplanır.

$C_{i}^{*}=\frac{S_{i}^{-}}{S_{i}^{-}+S_{i}{ }^{+}}$

$\operatorname{Adım} 7$ : Alternatifler $C_{i}^{*}$ değerine göre büyükten küçüğe sıralanır. En büyük değere sahip alternatif, en iyi seçimdir.

\section{Uygulama}

Çalışmada ülkelerin yaşam kalitesinin belirlenmesinde etkili olduğu düşünülen dokuz farklı kriterin belirlenmesinin ardından, uzmanlarla görüşmeler yapılarak fikirleri toplanmıştır. Uzmanlar seçilirken farklı alanlarda ve farklı tecrübe seviyelerinde olmasına dikkat edilmiştir. Devamında, uzmanların kriterler hakkında kıyaslamalarını yaptıkları ikili kıyaslama matrisleri Modifiye Delphi yöntemi ile konsolide edilerek tek bir matrise indirgenmiş̧ir. Elde edilen karar matrisi, Pisagor Bulanık AHP yöntemi ile değerlendirilerek her bir kriterin ağırlığı belirlenmiştir. Kriter ağıllıklarının elde edilmesinin ardından, otuz bir AB üyesi ülke TOPSIS yöntemi kullanılarak, yaşam kalitesine göre sıralanmıştır.

\subsection{Kriter Ağırlıklarının Belirlenmesi}

Ülkelerin yaşam kalitelerini değerlendirmek üzere ele alınan her bir kriterin önemi, Pisagor Bulanık AHP yöntemi kullanılarak elde edilmiş̧ir. Farklı alanlardan dokuz farklı uzmanın bu kriterler hakkındaki görüşleri yüz yüze görüşmeler yapılarak toplanmıştır. Uzmanların kriter kıyaslamaları daha sonra Modifiye Delphi yöntemi yardımıyla konsolide edilerek ikili kıyaslamalar tek matrise indirgenerek yapılmıştır. Uzmanların ana kriterler hakkındaki sözlü ifadelerini bulanık sayı olarak ifade edebilmek için Tablo 1'de gösterilen on puanlık ölçek (Ak ve Gül, 2019) kullanılmıştır.

Tablo 1. Dilsel değişkenlerin tanımı ve Pisagor bulanık ölçekleri

\begin{tabular}{ccccc}
\hline Dilsel Değişken & \multicolumn{4}{c}{ Aralıklı Pisagor Bulanı Sayılar } \\
\cline { 2 - 5 } & $\mu_{L}$ & $\mu_{U}$ & $v_{L}$ & $v_{U}$ \\
\hline \hline Kesinlikle Düşük Önemli (KD) & 0.0 & 0.0 & 0.9 & 1.0 \\
Çok Düşük Önemli (ÇD) & 0.1 & 0.2 & 0.8 & 0.9 \\
Düşük Önemli (D) & 0.2 & 0.35 & 0.65 & 0.8 \\
Ortalamanın Altında Önemli (OA) & 0.35 & 0.45 & 0.55 & 0.65 \\
Eşit (E) & 0.1965 & 0.1965 & 0.1965 & 0.1965 \\
Ortalama Önemli (O) & 0.45 & 0.55 & 0.45 & 0.55 \\
Ortalamanın Üstünde Önemli (OÜ) & 0.55 & 0.65 & 0.35 & 0.45 \\
Yüksek Önemli (Y) & 0.65 & 0.8 & 0.2 & 0.35 \\
Çok Yüksek Önemli (ÇY) & 0.8 & 0.9 & 0.1 & 0.2 \\
Kesinlikle Yüksek Önemli (KY) & 0.9 & 1.0 & 0.0 & 0.0 \\
\hline
\end{tabular}

Kriterlerin ikili karşılaş̧ırmaları dilsel değişkenler kullanılarak çalışmaya katılan uzmanlar tarafından Modifiye Delphi yöntemi ile oluşturulmuştur. Kriterlerin ikili kıyaslamalar matrisi Tablo 2'de gösterilmektedir.

Tablo 2. Kriterlerin ikili klyaslama matrisi

\begin{tabular}{|c|c|c|c|c|c|c|c|c|c|}
\hline & $\begin{array}{c}\text { Maddi } \\
\text { Yaşam } \\
\text { Koşulları } \\
\end{array}$ & Barımma & $\begin{array}{c}\text { Çalış̧ma } \\
\text { Durumu }\end{array}$ & Ĕ̆itim & Sağlık & $\begin{array}{c}\text { Sosyal } \\
\text { İlişkiler }\end{array}$ & Güvenlik & Yönetim & Çevre \\
\hline $\begin{array}{c}\text { Maddi } \\
\text { Yaşam } \\
\text { Koşulları }\end{array}$ & E & E & OÜ & $\mathrm{E}$ & D & OÜ & D & OA & E \\
\hline Barınma & E & E & OÜ & OA & D & $\mathrm{O}$ & D & OA & $\mathrm{OA}$ \\
\hline $\begin{array}{l}\text { Çalışma } \\
\text { Durumu }\end{array}$ & $\mathrm{OA}$ & OA & E & D & ÇD & E & ÇD & D & D \\
\hline Ĕ̆itim & $\mathrm{E}$ & $\mathrm{O}$ & Y & E & D & OÜ & OA & OA & OA \\
\hline Sağlık & Y & Y & ÇY & Y & E & ÇY & $\mathrm{O}$ & OÜ & OÜ \\
\hline $\begin{array}{c}\text { Sosyal } \\
\text { İlişkiler }\end{array}$ & OA & OA & E & $\mathrm{OA}$ & ÇD & E & D & OÜ & D \\
\hline Güvenlik & Y & $\mathrm{Y}$ & ÇY & OÜ & OA & Y & E & $\mathrm{O}$ & OÜ \\
\hline Yönetim & OÜ & OÜ & $\mathrm{Y}$ & OÜ & $\mathrm{OA}$ & $\mathrm{Y}$ & E & E & $\mathrm{E}$ \\
\hline Çevre & $\mathrm{O}$ & OÜ & Y & $\mathrm{O}$ & OA & Y & $\mathrm{OA}$ & E & E \\
\hline
\end{tabular}


Tablo 2'de yer alan ikili kıyaslamalar matrisinde yer alan değerler Pisagor Bulanık AHP yönteminde kullanılmış ve her bir kriterin ağırlığı Tablo 3’teki gibi elde edilmiştir.

Tablo 3. Kriter ă̆ırlıklarl

\begin{tabular}{lc}
\hline Kriterler & Kriter ağırlıkları \\
\hline \hline Maddi Yaşam Koşulları & 0,065 \\
Barınma & 0,049 \\
Çalışma Durumu & 0,028 \\
Eğitim & 0,078 \\
Sağllk & 0,285 \\
Sosyal İlişkiler & 0,043 \\
Güvenlik & 0,212 \\
Yönetim & 0,129 \\
Çevre & 0,110 \\
\hline
\end{tabular}

Çalışmada yer alan uzmanların görüşleri neticesinde, ülkelerin yaşam kalitesinin belirlenmesinde en önemli kriterler \%28,5 önem derecesine sahip "Sağllk" kriteri ve \%21,2 önem derecesine sahip "Güvenlik" kriteridir. Çalışmada ele alınan dokuz kriterden beş tanesi \%10’un altında önem derecesine sahip iken, en düşük önem derecesine sahip kriter \%2,8 ile "Çalışma Durumu" olarak tespit edilmiştir.

\section{1. Ülkelerin Yaşam Kalitelerine Göre Suralanması}

Kriter ağırlıklarının belirlenmesinin ardından Avrupa Birliği'nde yer alan otuz bir ülke daha önceki bölümlerde anlatılan TOPSIS yöntemi kullanılarak sıralanmıştır. Yöntemde kriter ağırlıkları olarak Tablo 3’te verilen ağırlıklar kullanılmıştır. Belirlenen kriterler baz alınarak ülke değerleri için Avrupa Birliği’nin resmi istatistik sitesinde (URL-1) yer alan indeks değerleri kullanılmıştır. Otuz bir ülkenin TOPSIS yöntemiyle kullanılarak oluşturulan yaşam kalitesi sıralaması ve çalışma sonucunda elde edilen TOPSIS sonuç değerleri Tablo 4'te verilmiştir.

Tablo 4. Ülkelerin yaşam kalitelerine göre sıralaması

\begin{tabular}{cccccc}
\hline Siralama & Ülke & Değer & Siralama & Ülke & Değer \\
\hline $\mathbf{1}$ & Norveç & 0,926 & $\mathbf{1 7}$ & Estonya & 0,722 \\
$\mathbf{2}$ & Danimarka & 0,914 & $\mathbf{1 8}$ & Fransa & 0,708 \\
$\mathbf{3}$ & İsviçre & 0,911 & $\mathbf{1 9}$ & Yunanistan & 0,678 \\
$\mathbf{4}$ & Finlandiya & 0,910 & $\mathbf{2 0}$ & Litvanya & 0,673 \\
$\mathbf{5}$ & İsveç & 0,898 & $\mathbf{2 1}$ & Polonya & 0,667 \\
$\mathbf{6}$ & Hollanda & 0,877 & $\mathbf{2 2}$ & Çekya & 0,666 \\
$\mathbf{7}$ & Avusturya & 0,840 & $\mathbf{2 3}$ & İtalya & 0,664 \\
$\mathbf{8}$ & İzlanda & 0,839 & $\mathbf{2 4}$ & Kibris & 0,664 \\
$\mathbf{9}$ & İngiltere & 0,799 & $\mathbf{2 5}$ & Slovakya & 0,650 \\
$\mathbf{1 0}$ & Romanya & 0,796 & $\mathbf{2 6}$ & Letonya & 0,649 \\
$\mathbf{1 1}$ & Lüksemburg & 0,768 & $\mathbf{2 7}$ & İspanya & 0,643 \\
$\mathbf{1 2}$ & Malta & 0,765 & $\mathbf{2 8}$ & Hirvatistan & 0,620 \\
$\mathbf{1 3}$ & Belçika & 0,764 & $\mathbf{2 9}$ & Bulgaristan & 0,592 \\
$\mathbf{1 4}$ & Almanya & 0,762 & $\mathbf{3 0}$ & Slovenya & 0,592 \\
$\mathbf{1 5}$ & İrlanda & 0,759 & $\mathbf{3 1}$ & Portekiz & 0,553 \\
$\mathbf{1 6}$ & Macaristan & 0,728 & & & \\
\hline
\end{tabular}

Tablo 4 incelendiğinde, dört ülkenin 0,900'den yüksek değere sahip olmasından dolayı, yüksek yaşam kalitesi vadettiği söylenebilir. Ayrıca ele alınan ülkelerin genel olarak birbirlerine çok yakın değerlere sahip olduğu görülmektedir.

\section{Bulgular}

Ülkelerin yaşam kalitesi sonuçları incelendiğinde Norveç 0,926 değer ile ilk sırada, Danimarka ise 0,914 değer ile ikinci sırada yer almıştır. Bunun sebebi olarak, Norveç'in ele alınan dokuz kriterden "Yönetim" kriterinde en yüksek değere sahip olması ve diğer sekiz kriterde de oldukça yüksek değerlere sahip olması gösterilebilir. Danimarka ise "Maddi Yaşam Koşulları", "Barınma", "Çalışma Durumu" ve "Eğitim" kriterlerinde en yüksek değere sahip olmasına rağmen bu kriterlerin önem derecelerinin görece düşük olmasından dolayı ikinci sırada yer almıştır. Üçüncü sırada yer alan İsviçre ve dördüncü sırada yer alan Hollanda arasında çok küçük bir fark vardır. Her iki ülke "Sağlık" kriterinde en yüksek iki değere sahip iken, diğer tüm kriterlerde de ortalama üstü değerlere sahiptir. 
Diğer ülkelere nazaran yüksek yaşam kalitesi skorlarına sahip bu dört ülkenin, çalışmada kullanılan yöntem doğrultusunda, en iyi yaşam kalitesine sahip ülkeler olduğu belirlenmiştir. Bu durumun sağlanmasında, belirlenen dokuz kriterin sekiz tanesinde ilgili ülkelerin en yüksek değerlere sahip olması ve diğer tüm kriterlerde ortalamanın üstünde değerlere sahip olması önemli rol oynamıştır. $\mathrm{Bu}$ da önerilen yöntemin etkin sonuçlar vermesi anlamında önemlidir.

Sıralamada ilk sekiz ülkeye odaklanıldığı takdirde, tüm ülkelerin Avrupa'nın kuzeyinde yer aldığı görülmektedir. Buradan Avrupa'nın kuzey bölgelerinde yaşam kalitesinin daha yüksek olduğu anlamı çıkarılabilir. Çalışmada son sırada ise Portekiz yer almıştır. $\mathrm{Bu}$ duruma sebebiyet veren kriterler "Sağlık" ve "Çevre" kriterleri olarak görülmektedir. Uzmanların en çok önemsediği "Sağllk" kriterinde düşük değere sahip olması, Portekiz'in son sırada yer almasının temel sebebi olarak gösterilebilir. Çalışma sonucunda elde edilen bu değerler, yaşam kalitesi bakımından yetersiz olarak görülen ülkeler için odaklanılması gereken noktalara yol gösterici olabilir.

\section{Sonuç}

Çalışmada ülkelerin yaşam kalitesinin belirlenmesi amaçlanmıştır. Bu amaç dahilinde yaşam kalitesini etkileyen kriterleri belirlemek için ilk olarak Avrupa Birliği'nin yayınladığı kriterler dikkate alınmıştır. Devamında literatür taraması yapılmış ve konu hakkında tecrübeli uzmanlardan geri dönüşler alınarak kriterler belirlenmiştir. Uzmanların bu kriterler hakkındaki görüşleri yüz yüze görüşmeler yapılarak toplanmıştır. Bu görüşler Modifiye Delphi yöntemi ile konsolide edilmiş ve ele alınan her bir kriterin önemi, Pisagor Bulanık AHP yöntemi kullanılarak elde edilmiştir. Yöntem sonuçlarına göre en önemli kriter "Sağllk" olarak belirlenmiştir. Çalışmanın devamında Avrupa Birliği'nde yer alan otuz bir ülke TOPSIS yöntemi ile kıyaslanmış elde edilen sonuçlar analiz edilmiştir.

Çalışmanın literatüre katkısı şu şekilde tanımlanabilir: (1) Pisagor Bulanık AHP yöntemi ülkelerin yaşam kalitesinin değerlendirmesine adapte edilmiştir; (2) Kriterler literatür taraması ve uzman görüşleriyle belirlenmiştir; (3) Modifiye Delphi yöntemiyle çok sayıda uzmanın görüşü birleştirilmiş̧tir; (4) Ana kriterler Pisagor Bulanık AHP yöntemi ile ağırlıklandırılmış ve önem dereceleri belirlenmiştir; (5) Avrupa Birliği üyesi otuz bir ülke TOPSIS yöntemi kullanılarak yaşam kalitesine göre sıralanmıştır; (6) Yaşam kaliteisni belirlemede önemli kriterlerler göre, ülkelerin geliştirmeleri gereken yönler belirlenmiştir.

Gelecek çalışmalar için ele alınan ülke sayısı artırılabilir, daha fazla kritere odaklanılabilir, alt kriterler genişletilerek çalışma için daha çok parametrenin dikkate alınması sağlanabilir. Kıyaslama açısından güçlü olması adına diğer bulanık karar verme yöntemleri veya sezgisel yöntemler probleme dahil edilebilir.

\section{Kaynakça}

Ayyildiz E., \& Demirci, E. (2018). Türkiye'de Yer Alan Şehirlerin Yaşam Kalitelerinin Swara Entegreli Topsıs Yöntemi İle Belirlenmesi. Pamukkale University Journal of Social Sciences Institute/Pamukkale Üniversitesi Sosyal Bilimler Enstitüsü Dergisi, (30).

Halvari, A. E. M., Halvari, H., \& Deci, E. L. (2019). Dental anxiety, oral health-related quality of life, and general well-being: A selfdetermination theory perspective. Journal of Applied Social Psychology, 49(5), 295-306.

Whoqol Group, (1998). Development of the World Health Organization WHOQOL-BREF quality of life assessment. Psychological medicine, 28(3), 551-558.

OffringA, G., ve De Wet, G. (1996). A quality of life-based decision support model for the determination of water research priorities. Water SA, 22(4), 359-372.

Jeon, C. M., Amekudzi, A. A., ve Guensler, R. L. (2010). Evaluating plan alternatives for transportation system sustainability: Atlanta metropolitan region. International Journal of Sustainable Transportation, 4(4), 227-247.

Chen, T. (2011). Using hybrid MCDM model for enhancing the participation of teacher in recreational sports. Journal of Decision Systems, 20(1), 33-49.

Mullıner, E., Smallbone, K., ve Malıene, V. (2013). An assessment of sustainable housing affordability using a multiple criteria decision making method. Omega, 41(2), 270-279.

Anand, A., Rufuss, D. D. W., Rajkumar, V., ve Suganth1, L. (2017). Evaluation of sustainability indicators in smart cities for India using MCDM approach. Energy Procedia, 141, 211-215.

Devlin, N. J., Shah, K. K., Feng, Y., Mulhern, B., \& van Hout, B. (2018). Valuing health-related quality of life: An EQ-5 D-5 L value set for E ngland. Health economics, 27(1), 7-22.

Silverberg, J. I., Gelfand, J. M., Margolis, D. J., Boguniewicz, M., Fonacier, L., Grayson, M. H., ... \& Fuxench, Z. C. C. (2018). Patient burden and quality of life in atopic dermatitis in US adults: a population-based cross-sectional study. Annals of Allergy, Asthma \& Immunology, 121(3), 340-347.

Wann-Ming, W. (2019). Constructing urban dynamic transportation planning strategies for improving quality of life and urban sustainability under emerging growth management principles. Sustainable Cities and Society, 44, 275-290.

Wong, P. C., Hsieh, Y. P., Ng, H. H., Kong, S. F., Chan, K. L., Au, T. Y. A., ... \& Fung, X. C. (2019). Investigating the Self-Stigma and Quality of Life for Overweight/Obese Children in Hong Kong: a Preliminary Study. Child Indicators Research, 12(3), 1065-1082.

Zarghamı, E., Sharghı, A., Olfat, M., ve Kousaları, F. S. (2018). Using Multi-Criteria Decision-Making Method (MCDM) to Study Quality of Life Variables in the Design of Senior Residences in Iran. Ageing International, 43(3), 279-296.

URL-1 https://ec.europa.eu/eurostat/statistics-explained/index.php/Quality_of life indicators

Gümüş, A. T. (2009). Evaluation of hazardous waste transportation firms by using a two step fuzzy-AHP and TOPSIS methodology. Expert systems with applications, 36(2), 4067-4074.

Zadeh, L. A., (1965), Information and control, Fuzzy sets, 8(3), 338-353.

Wang, J. Q., Peng, J. J., Zhang, H. Y., Liu, T., Chen, X. H., (2015), An uncertain linguistic multi-criteria group decision-making method based on a cloud model, Group Decision and Negotiation, 24(1), 171-192. 
Yager, R. R., (2013), Pythagorean membership grades in multicriteria decision making. IEEE Transactions on Fuzzy Systems, 22(4), 958-965.

Gül, M., ve Ak, M. F. (2018). A comparative outline for quantifying risk ratings in occupational health and safety risk assessment. Journal of cleaner production, 196, 653-664.

Karaşan, A., İlbahar, E., Çebİ, S., ve Kahraman, C., (2018), A new risk assessment approach: Safety and Critical Effect Analysis (SCEA) and its extension with Pythagorean fuzzy sets, Safety science, 108, 173-187.

Mohagheghı, V., Mousav1, S. M., ve Vahdanı, B., (2017), Enhancing decision-making flexibility by introducing a new last aggregation evaluating approach based on multi-criteria group decision making and Pythagorean fuzzy sets. Applied Soft Computing, 61, 527535.

Çavdur, F., Sebatlı, A., Ve KÜÇÜK, M. K. , (2019), Öğrenci-proje takımı oluşturma problemi için grup-karar verme ve hedef programlama temelli çözüm yaklaşımı. Journal of the Faculty of Engineering and Architecture of Gazi University, 34(1), 505-521.

Yerlikaya, M. A., ve Arıkan, F., (2016), KOBİ’lere sağlanan desteklerin performans etkinlik sıralarının Promethee ve Oreste yöntemleri ile belirlenmesi enmesi. Journal of the Faculty of Engineering and Architecture of Gazi University, 31(4), 1007-1016.

Ecer, F., Kınay, A., Nasiboğlu, E., (2018). Ahp Yöntemi İle Engelli Bireye Sahip Ailelerin Standart Hayat Şartlarına Ulaşabilmeleri İçin Gerekli Finansal Desteğin Belirlenmesi. Mehmet Akif Ersoy Üniversitesi İktisadi ve İdari Bilimler Fakültesi Dergisi, 5(3), 687704.

Lıu, P. D., ve Jın, F., (2012), The trapezoid fuzzy linguistic Bonferroni mean operators and their application to multiple attribute decision making. Scientia Iranica, 19(6), 1947-1959.

Hwang, C. L., ve YOON, K. (2012). Multiple attribute decision making: methods and applications a state-of-the-art survey (Vol. 186). Springer Science ve Business Media.

Yalçınkaya, Y, Dulupçu, M, BaykuL, A. (2018). Topsıs Yöntemi İle Organize Sanayi Bölgelerinin Yatırım Ortamının Değerlendirilmesi: İbbs Düzey 3 Üzerine Bir Uygulama. Mehmet Akif Ersoy Üniversitesi İktisadi ve İdari Bilimler Fakültesi Dergisi, 5 (1), 90-107.

Oruç, K. O., ve Kılınç, M. (2019). Suriyeli Sığınmacılar için Uygun Ev Sahibi Ülkelerin Çok Kriterli Karar Verme Yöntemleri ile Belirlenmesi. Mehmet Akif Ersoy Üniversitesi İktisadi ve İdari Bilimler Fakültesi Dergisi, 5(2), 223-244.

Alızadeh, S., Rad, M. M. S., ve Bazzazi, A. A. (2016). Alunite processing method selection using the AHP and TOPSIS approaches under fuzzy environment. International Journal of Mining Science and Technology, 26(6), 1017-1023.

Ak, M. F., ve Gül, M., (2019), AHP-TOPSIS integration extended with Pythagorean fuzzy sets for information security risk analysis. Complex and Intelligent Systems, 5(2), 113-126. 